\title{
Measurement and Evaluation of Hydrogen Production from Mixtures of Seawater and Zeolite in Decontamination of Radioactive Water
}

\author{
Yuta KUMAGAI ${ }^{1, *}$, Ryuji NAGAISHI ${ }^{1}$, Atsushi KIMURA ${ }^{2}$, \\ Mitsumasa TAGUCHI $^{2}$, Kenji NISHIHARA ${ }^{1}$, Isao YAMAGISHI ${ }^{1}$ \\ and Toru OGAWA ${ }^{1}$ \\ ${ }^{1}$ Nuclear Science and Engineering Directorate, Japan Atomic Energy Agency, 2-4 Shirane, Shirakata, Tokai-mura, \\ Naka-gun, Ibaraki 319-1195, Japan \\ ${ }^{2}$ Quantum Beam Science Directorate, Japan Atomic Energy Agency, 1233 Watanuki-machi, Takasaki-shi, Gunnma \\ 370-1292, Japan
}

\begin{abstract}
Zeolite is used for the decontamination of radioactive water, which contains salts from seawater, accumulated in the Fukushima Daiichi Nuclear Power Plant. The evaluation of hydrogen production by water radiolysis during the decontamination process is important for safe operation. Thus, hydrogen production from a mixture of zeolite and seawater was studied by a $\gamma$-radiolysis experiment, and the hydrogen production during the process was evaluated. The measured yield of hydrogen from seawater was comparable to the primary yield in the $\gamma$-radiolysis of water. This result indicates that the oxidation of hydrogen by the radical products of water radiolysis is not effective in seawater. The measured yield from the mixture decreased at a high weight fraction of zeolite. However, the measured yield was higher than that expected from the direct radiolysis of water in the mixture, which would decrease proportionally to the weight fraction of water. This result suggests that the radiation energy deposited on the zeolite is involved in hydrogen production. From the measured yields, the hydrogen production rate was evaluated to be $3.6 \mathrm{~mL} / \mathrm{h}$ per $\mathrm{t}$ of radioactive water before the process and $1.5 \mathrm{~L} / \mathrm{h}$ per $\mathrm{t}$ of waste adsorbent after the process.
\end{abstract}

KEYWORDS: hydrogen, radiolysis, zeolite, seawater, radioactive contaminated water, decontamination

\section{Introduction}

Inorganic adsorbents have been extensively studied in the removal of radioactive cesium and strontium from contaminated water and used in the treatment of the radioactive water from the Fukushima Daiichi Nuclear Power Plant (1F). Before practical application, safety during the adsorbing treatment and the temporary storage of radioactive waste after treatment must be evaluated. Under radiation environment, hydrogen is produced by the decomposition

\footnotetext{
${ }^{*}$ Corresponding author, E-mail: kumagai.yuta@jaea.go.jp

DOI : 10.15669 /fukushimainsights.Vol.4.37

(C) 2021 Atomic Energy Society of Japan. All rights reserved.

Originally published in Transactions of the Atomic Energy Society of Japan (ISSN 1347-2879), Vol. 10, No. 4, p.235-239

(2011) in Japanese. (Japanese version accepted: July 26, 2011)
} 
of water. Previous studies have pointed out that various inorganic solid substances affect the hydrogen production from the radiolysis of water ${ }^{1-4)}$. This radiolytic hydrogen production must be considered to ensure safety during and after treatment. Furthermore, the contaminated water in $1 \mathrm{~F}$ includes a considerable quantity of salts from seawater. The presence of salts makes the situation different from that experienced in the reactor water treatment ${ }^{5,6}$ after the accident at Three Mile Island Unit 2.

Hence, in this study, we focused on zeolites that are potential inorganic adsorbents mainly for radioactive cesium to conduct irradiation experiments and evaluate the quantity of hydrogen produced from the mixture of zeolites and seawater. Furthermore, we evaluated the radiolytic hydrogen production from the zeolite-seawater mixtures at elevated temperatures, because a temperature rise in the spent adsorbents is expected because of the decay heat of radioactive nuclide during the temporary storage.

\section{Experimental Methodology}

The mixtures of zeolite-type adsorbents and seawater were irradiated by $\gamma$-ray in a vial with a septum. After irradiation, the gas in the upper free space in the vial was analyzed by gas chromatography and hydrogen in the gas phase was determined.

The details of the experimental methodology are described below:

The zeolite-type adsorbents used in this study were Herschelite (bulk density $0.65 \mathrm{~g} / \mathrm{mL}$ ), engineered Herschelite (hereafter referred to as "E-Herschelite", $0.65 \mathrm{~g} / \mathrm{mL}$ ) provided by KURION, and natural mordenite mined in Ayashi by Shin Tohoku Chemical Industry ( $0.8 \mathrm{~g} /$ $\mathrm{mL}$ ). The seawater was sampled in Oarai Seaside, Ibaraki Prefecture, and filtrated through a filter paper (5C) before use.

In practical application, zeolite-type adsorbents may be used in batch processes or in column systems. Therefore, we prepared samples containing $1 \mathrm{wt} \%$ of adsorbents for simulating the batch processes and samples containing approximately $50 \mathrm{wt} \%$ of the adsorbents for simulating the column systems and the spent adsorbents during temporary storage. The adsorbents in the 1 $\mathrm{wt} \%$ samples settled on the bottom of the vials. The $50 \mathrm{wt} \%$ samples were prepared by gradually adding the seawater to the adsorbents until the seawater filled up the vacant space between the adsorbent grains. The adsorbents were weighed under a condition of approximately $40 \%$ relative humidity. Note that the adsorbents contained adsorbed water because they were not dehydrated before use. Each sample vial contained $3 \mathrm{~g}$ to $9 \mathrm{~g}$ of the mixture to produce sufficient hydrogen for measurement. The samples were sealed in glass vials with a septum. The vial used for the measurement at room temperature had a diameter of $23 \mathrm{~mm}$ and a volume of $8.7 \mathrm{~mL}$. For the measurements of temperature dependence, the sample vial was $12 \mathrm{~mm}$ in diameter and had a volume of $5.15 \mathrm{~mL}$. The septum was made of silicon and coated with Teflon on the liquid contacting surface. The atmosphere and pressure of the samples were not controlled and the upper free space was filled with air.

The cobalt irradiation facility of the Takasaki Advanced Radiation Research Institute was used for irradiating the $\gamma$-ray (mean energy $1.25 \mathrm{MeV}$ ) from the ${ }^{60} \mathrm{Co}$ radiation source on the specimen. During irradiation, the specimen was left in a static condition and was not stirred. The dose rate was adjusted in the range of $2 \mathrm{kGy} / \mathrm{h}$ to $5 \mathrm{kGy} / \mathrm{h}$ to obtain an irradiation time fewer than 2 hours with a range of absorbed dose rate from $1 \mathrm{kGy}$ to $10 \mathrm{kGy}$. A dichromate dosimeter was used for measuring the absorbed dose rate ${ }^{7)}$. For irradiating under a controlled temperature, an aluminum block isothermal bath (TAITEC) was used. 
After stirring the specimen after irradiation for $2 \mathrm{~min}$ at a speed of 3,000 rpm using a vortex mixer, the gas in the upper free space in the vial was sampled with a microsyringe and analyzed using the gas chromatograph (GC14A/Shimadzu) and the hydrogen concentration in the upper free space was measured. For the gas chromatograph analyses, a column of bulking agent molecular sieve $5 \mathrm{~A}$ with a $4 \mathrm{~m}$ long column was used for the measurement of hydrogen using a TCD detector with pure argon as a carrier gas. Furthermore, to determine the volume of the upper free space, pure water was added until the container was filled with the specimen after measurement and the weight increase was measured. Four rounds of measurements were conducted for specimens of identical composition, and an average of the volume of the upper free space was determined. The specific weight of pure water was assumed to be $1.00 \mathrm{~g} / \mathrm{mL}$. The errors were not more than $0.1 \mathrm{~mL}$ for a vial with a volume of $8.7 \mathrm{~mL}$, and not more than $0.06 \mathrm{~mL}$ for a vial with a volume of $5.15 \mathrm{~mL}$. These errors were not more than $3 \%$ of the average of the volume of upper free space. The quantity of hydrogen emitted from the specimen was measured using the hydrogen concentration and the volume of the vial's upper free space.

\section{Hydrogen Production Quantity due to the Radiolysis of Seawater}

First, the result of the measurement of hydrogen production due to the radiolysis of seawater is explained. The hydrogen production quantity of a specimen that consisted only of seawater was proportional to the absorbed dose and the measured yield $G\left(\mathrm{H}_{2}\right)$ was $(4.8 \pm 0.3) \times 10^{-8} \mathrm{~mol} / \mathrm{J}$. Hereafter, the measured hydrogen yield as a final product and the primary yield of hydrogen produced by the radiolysis of water are distinguished as $G\left(\mathrm{H}_{2}\right)$ and $\mathrm{g}\left(\mathrm{H}_{2}\right)$, respectively.

In the radiolysis of water, the production of hydrogen due to the reaction between the decomposition products progresses on a short timescale up to $0.1 \mu$ s from the energy transfer from the radiation to the water. The "primary yield $\mathrm{g}\left(\mathrm{H}_{2}\right)$ " is the yield of hydrogen at approximately $0.1 \mu \mathrm{s}$ after the energy transfer, and is $4.7 \times 10^{-8} \mathrm{~mol} / \mathrm{J}$ for $\gamma$-rays or electron beams that are classified as radiation with low linear energy transfer. Because the reaction of decomposition products and hydrogen still occurred $0.1 \mu$ s after the energy transfer, $G\left(\mathrm{H}_{2}\right)$ will be dependent on the reaction path of a decomposition product and ultimately takes a different value than $\mathrm{g}\left(\mathrm{H}_{2}\right)$. What is problematic in the treatment of contaminated water is the hydrogen released in the gas phase, and hence, $G\left(\mathrm{H}_{2}\right)$, not $\mathrm{g}\left(\mathrm{H}_{2}\right)$, becomes important in the evaluation of hydrogen production quantity.

A typical reaction that influences $G\left(\mathrm{H}_{2}\right)$ is the reaction with the hydroxylic radical $(\cdot \mathrm{OH})$ :

$$
\begin{aligned}
\mathrm{H}_{2}+\cdot \mathrm{OH} \longrightarrow \mathrm{H} \cdot+\mathrm{H}_{2} \mathrm{O} \\
\quad k_{(1)}=4.2 \times 10^{7} \mathrm{~L} \cdot \mathrm{mol}^{-1} \cdot \mathrm{s}^{-1}
\end{aligned}
$$

For example, it is known for deaerated pure water that the $G\left(\mathrm{H}_{2}\right)$ falls far below $4.7 \times$ $10^{-8} \mathrm{~mol} / \mathrm{J}$ due to this reaction ${ }^{8}$.

On the other hand, for potassium bromide solution, the oxidation of hydrogen via the reaction (1) is inhibited by the following reaction of the bromide ion and hydroxylic radical ${ }^{9,10)}$ :

$$
\begin{aligned}
\mathrm{Br}^{-}+\cdot \cdot \mathrm{OH} \rightleftarrows & \mathrm{BrOH}^{-} \\
& k_{(2) \mathrm{f}}=1.1 \times 10^{10} \mathrm{~L} \cdot \mathrm{mol}^{-1} \cdot \mathrm{s}^{-1} \\
& k_{(2) \mathrm{b}}=3.3 \times 10^{7} \mathrm{~s}^{-1}
\end{aligned}
$$




$$
\begin{aligned}
\mathrm{BrOH} & \cdot-+\mathrm{Br}^{-} \longrightarrow \mathrm{Br}_{2}^{--}+\mathrm{OH}^{-} \\
& k_{(3)}=1.9 \times 10^{8} \mathrm{~L} \cdot \mathrm{mol}^{-1} \cdot \mathrm{s}^{-1}
\end{aligned}
$$

In this experiment, it was confirmed that $G\left(\mathrm{H}_{2}\right)$ was $(4.6 \pm 0.2) \times 10^{-8} \mathrm{~mol} / \mathrm{J}$ because of the measurement of hydrogen production quantity in the deaerated $1 \mathrm{mmol} / \mathrm{L}$ potassium bromide solution.

Accordingly, the fact that the $G\left(\mathrm{H}_{2}\right)$ equivalent to the $\mathrm{g}\left(\mathrm{H}_{2}\right)$ measured in the specimen consisting only of seawater was similar to that of the potassium bromide solution, implies that the oxidation reaction of hydrogen was inhibited in the seawater. Regarding the mechanism, a more detailed study into the effect of dissolved species in seawater is needed. But, according to the analysis by Bjergbakke et al ${ }^{11}$., it is considered that the main reason for the effect is the reaction between the bromide ions, chloride ions, and the decomposition product of oxygen and water in the seawater.

\section{Hydrogen Production Quantity from Adsorbent-Seawater Mixture}

In this section, the influence of zeolite type adsorbent addition on the hydrogen production quantity is explained. The results of the measurements on hydrogen production quantity for the mixture of various zeolite types in the adsorbent and seawater are shown in Figure 1. The vertical axis in the figure is the hydrogen quantity released from the unit weight of the mixture. Because the absorbed dose was different due to the difference of the mass energy absorption coefficient between the adsorbent and water, even if the radiation fields were identical, a correction was applied to the absorbed dose on the horizontal axis in the figure. The absorbed dose measurement of the adsorbent was obtained using a dosimeter with a photon mass energy absorption coefficient of $1.25 \mathrm{MeV}$. The absorbed dose of the mixture was defined as the weighted sum with weight percent on the absorbed dose of adsorbent and water, i.e., the absorbed dose $D(\mathrm{kGy})$ of the mixture was acquired using the equation below:

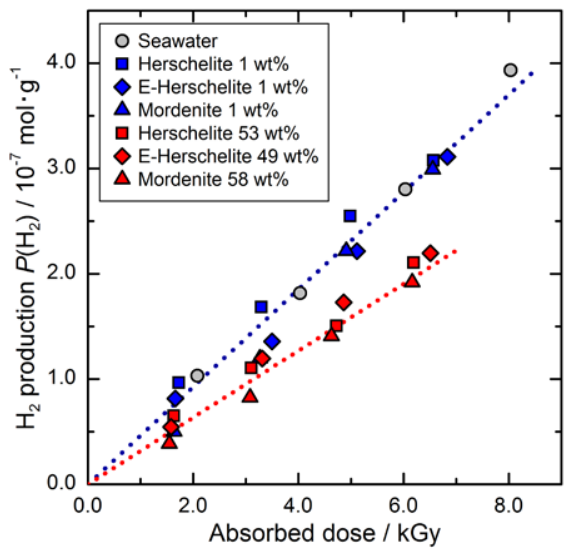

Figure 1 Hydrogen production by radiolysis of the zeolites and seawater mixtures Blue dotted line: linear fit for the samples containing $1 \mathrm{wt} \%$ zeolites. Red dotted line: linear fit for the samples containing approximately $50 \mathrm{wt} \%$ zeolites 


$$
D=D_{\text {solid }} \cdot w_{\text {solid }}+D_{\text {water }} \cdot w_{\text {water }}
$$

where $w$ indicates the weight percentage, the suffix "solid" and "water" indicate the adsorbent and seawater, respectively. The difference in the absorbed doses between seawater and the dichromate potassium solution used as a dosimeter was ignored. The absorption coefficient of water is $2.97 \times 10^{-2} \mathrm{~cm}^{2} / \mathrm{g}$ and the absorption coefficient of aluminosilicate such as zeolite shows a low dependence on the composition at approximately $2.7 \times 10^{-2} \mathrm{~cm}^{2} / \mathrm{g}^{12)}$. Accordingly, the absorption dose of adsorbent $D_{\text {solid }}$ is lower than that of water $D_{\text {water }}$ by approximately $10 \%$.

The hydrogen production quantity from the mixture of adsorbent and seawater was equivalent to the specimen containing only seawater, regardless of the adsorbent types for the specimen containing $1 \mathrm{wt} \%$ of adsorbent. While the specimen of approximately $50 \mathrm{wt} \%$ showed a lower hydrogen production quantity compared to the specimen containing only seawater, there was not a notable difference observed in the dependence on the adsorbent type.

Where the absorbed dose was $10 \mathrm{kGy}$ and under, the hydrogen production quantity and absorbed dose showed an approximately proportional relationship. Hence, the hydrogen production yield was obtained through proportional regression of the hydrogen production quantity to the absorbed dose. The hydrogen production yield $G\left(\mathrm{H}_{2}\right)(\mathrm{mol} / \mathrm{J})$ and hydrogen production quantity $P\left(\mathrm{H}_{2}\right)(\mathrm{mol} / \mathrm{g})$ has a relationship described by the following equation:

$$
P\left(\mathrm{H}_{2}\right)=G\left(\mathrm{H}_{2}\right) \times D
$$

The values of $G\left(\mathrm{H}_{2}\right)$ acquired for the various specimens are summarized in Table $\mathbf{1}$.

\begin{tabular}{|c|c|c|}
\hline \multicolumn{2}{|c|}{ Sample } & \multirow{2}{*}{$\frac{G\left(\mathrm{H}_{2}\right) / 10^{-8} \mathrm{~mol} \cdot \mathrm{J}^{-1}}{4.9 \pm 0.2}$} \\
\hline Herschelite & $1 \mathrm{Wt} \%$ & \\
\hline & $53 \mathrm{wt} \%$ & $3.4 \pm 0.1$ \\
\hline \multirow[t]{2}{*}{ E-Herschelite } & $1 \mathrm{wt} \%$ & $4.4 \pm 0.2$ \\
\hline & $49 w t \%$ & $3.5 \pm 0.1$ \\
\hline \multirow[t]{2}{*}{ Mordenite } & $1 \mathrm{wt} \%$ & $4.4 \pm 0.3$ \\
\hline & $58 \mathrm{wt} \%$ & $3.0 \pm 0.1$ \\
\hline
\end{tabular}

Table $1 G\left(\mathrm{H}_{2}\right)$ measured in the mixtures of the zeolites and seawater

\section{Influence of Adsorbent on Hydrogen Production Yield}

In this experiment, no $G\left(\mathrm{H}_{2}\right)$ that exceeds $\mathrm{g}\left(\mathrm{H}_{2}\right)$ was observed for the mixture of adsorbent and seawater. However, the measured $G\left(\mathrm{H}_{2}\right)$ implied the influence of energy transfer from the radiations to the adsorbent on the radiolysis of water.

The dependence of $G\left(\mathrm{H}_{2}\right)$ to the weight ratio of adsorbent and seawater is shown in Figure 2. For comparison, a series of reports by Nakashima et al. regarding hydrous zeolite ${ }^{1-3)}$ are shown. As reported by Nakashima et al., $G\left(\mathrm{H}_{2}\right)$ was provided based on the weight ratio of zeolite dried at $350^{\circ} \mathrm{C}$ with moisture added. Nakashima et al. adopted the synthetic zeolite of type-A and type- $\mathrm{Y}$ with pure water added as specimens and investigated the hydrogen production quantity under a condition with less moisture content than that of this experiment. The blue and green solid lines in Figure 2 indicate the curves based on the evaluation formula for hydrogen production yield for type K-A and type Na-A zeolites by Nakashima et al., respectively. This evaluation formula assumes that hydrogen is produced with the yield of $4.7 \times 10^{-8} \mathrm{~mol} / \mathrm{J}$ from 


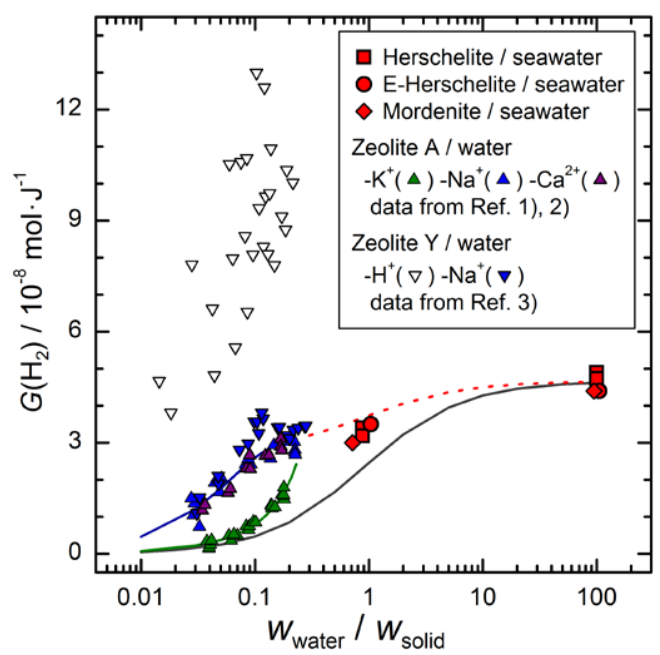

Figure 2 The yield of hydrogen as a final product, $G\left(\mathrm{H}_{2}\right)$, in the mixtures of the zeolites and water as a function of the weight ratio of water to zeolites Blue and green curves: formula by Nakashima and Aratono ${ }^{2)}$ Red dotted curve: extrapolation of the formula (Eq. 10) Gray curve: no $\mathrm{H}_{2}$ production from zeolites (Eq. 11)

the energy transferred to water and that the hydrogen production that occurs with the yield is dependent on the moisture content from the energy transferred to the zeolite ${ }^{1,2}$.

The results of the experiment by Nakashima et al. show the trend of convergence of the hydrogen production yield because of the energy transferred to the zeolite was $2.7 \times 10^{-8} \mathrm{~mol} / \mathrm{J}$ when the weight ratio of water to zeolite approached 0.25 for type A regardless of the contained cation ${ }^{2)}$. Hence, the evaluation formula by Nakashima et al. was extrapolated based on the assumption that the energy transferred to the zeolite contributed to hydrogen production with a certain yield of $2.7 \times 10^{-8} \mathrm{~mol} / \mathrm{J}$ in the range of higher moisture content and is indicated by the red dotted lines. The red dotted lines are the plots of $G\left(\mathrm{H}_{2}\right)$ obtained using the following equation:

$$
\begin{aligned}
P\left(\mathrm{H}_{2}\right) & =G\left(\mathrm{H}_{2}\right) \times \mathrm{D} \\
& =4.7 \times 10^{-8} \times D_{\text {water }} \cdot w_{\text {water }}+2.7 \times 10^{-8} \times D_{\text {solid }} \cdot w_{\text {solid }}
\end{aligned}
$$

Consequently, the red dotted line indicates the $G\left(\mathrm{H}_{2}\right)$ when it is assumed that the energy transferred to the zeolite produces hydrogen with approximately $60 \%$ efficiency compared to the energy transferred directly to the water.

The gray curve in Figure 2 is the plot of the following equation:

$$
\begin{aligned}
P\left(\mathrm{H}_{2}\right) & =G\left(\mathrm{H}_{2}\right) \times \mathrm{D} \\
& =4.7 \times 10^{-8} \times D_{\text {water }} \cdot w_{\text {water }}+0 \times D_{\text {solid }} \cdot w_{\text {solid }}
\end{aligned}
$$

More specifically, the gray curve in Figure 2 is equivalent to $G\left(\mathrm{H}_{2}\right)$ when only the energy transferred to the water in the mixture contributes to the hydrogen production with a yield of $4.7 \times 10^{-8} \mathrm{~mol} / \mathrm{J}$, and no hydrogen is produced from the energy transferred to the zeolite. However, based on the results of the measurements on specimens containing seawater only, the 
inhibition of hydrogen production by oxidation reaction was not considered.

Additionally, from the results of this experiment, it is evident that the value of the specimen with approximately $50 \mathrm{wt} \%$ of added adsorbent exceeds the anticipated $G\left(\mathrm{H}_{2}\right)$ from Eq. (11). For this reason, there is a possibility of underestimation when the hydrogen production quantity is evaluated using Eq. (11). Consequently, the evaluation that considers the hydrogen production from the energy transfer to the adsorbent, as shown in Eq. (10), is regarded as reasonable also for the mixture with seawater. However, because the weighed adsorbent contains the adsorbed water in this experiment, it was considered that the radiolysis of the adsorbed water also contributed to a higher observed value of $G\left(\mathrm{H}_{2}\right)$ than was predicted by Eq. (11).

The necessity for the consideration of hydrogen production caused by the energy transfer to the adsorbent was also indicated by the accident report of Three Mile Island Unit $2^{6}$. According to the report, due to the measurement of the hydrogen production quantity from the zeolite filled column used for reactor water treatment after the accident, the hydrogen production quantity was not regarded to be dependent on the moisture content in the range of water weight ratio to zeolite $0.2-0.7$.

The experiment results by Nakashima et al. report that, as shown in Figure 2, a higher $G\left(\mathrm{H}_{2}\right)$ was observed when the entrapped positive ion was the hydrogen ion. In a similar phenomenon, in the hydrogen production of a mixture of silica or alumina with water solution, a remarkably high hydrogen production quantity was reported under an acidic condition using sulfuric acid ${ }^{4}$. Accordingly, the hydrogen production quantity may increase under an acidic condition, but this was not presumed to be the case in the contaminated water treatment related to the Fukushima Daiichi Nuclear Power Station.

\section{Influence of the Specimen Temperature on Hydrogen Production Yield}

The temperature dependence of the hydrogen production quantity was measured for the mixture of Herschelite or mordenite and seawater. The temperatures for the experiments were the room temperature $\left(16 \pm 3^{\circ} \mathrm{C}, 40 \pm 1^{\circ} \mathrm{C}\right.$, and $\left.60 \pm 1^{\circ} \mathrm{C}\right)$. As a result, no significant temperature variation was observed on $G\left(\mathrm{H}_{2}\right)$ in the temperature range of the experiments, and the variations fell within the experimental error.

The primary yield of hydrogen due to the radiolysis of water $\mathrm{g}\left(\mathrm{H}_{2}\right)$ is known to vary little in the temperature range of these experiments ${ }^{13}$. Consequently, the fact that no significant temperature dependence was observed on the $G\left(\mathrm{H}_{2}\right)$ for the specimens containing only seawater indicates that the oxidation reaction of hydrogen in seawater was also ineffective at $60^{\circ} \mathrm{C}$. Furthermore, because no significant temperature dependence was observed on the $G\left(\mathrm{H}_{2}\right)$ for specimens with the adsorbent and seawater mixture, the hydrogen production due to energy transfer to absorbent was similarly regarded as not significantly temperature dependent.

\section{Evaluation of Hydrogen Production Ratio Assuming the Contaminated Water Treatment}

Assuming the treatment of contaminated water using zeolite type adsorbent, the production ratio of hydrogen emitted in the gas phase in each step of treatment was evaluated in the 
following manner.

First, based on the result of the nuclide analysis conducted on the contaminated water from the basement of the turbine building in Unit 2 of the Fukushima Daiichi Nuclear Power Plant ${ }^{14}$, the absorbed dose rate of the analyzed contaminated water was approximately $3.3 \mathrm{~Gy} / \mathrm{h}$ excluding ${ }^{131} \mathrm{I}$ with short half-life ${ }^{15)}$ —assuming that all $\beta$-rays and $\gamma$-rays from the radioactive nuclide were absorbed by the contaminated water. The oxidation of hydrogen in the contaminated water seems to be prohibited by the influence of the dissolved species in the seawater. For this reason, a similar level of yield as $\mathrm{g}\left(\mathrm{H}_{2}\right)$ should be expected assuming that all produced hydrogen is released in the gas phase. Here, the hydrogen production ratio before and during treatment with the batch method was estimated by regarding the hydrogen production yield as $4.9 \times 10^{-8} \mathrm{~mol} / \mathrm{J}$ based on the result of the specimen of seawater and $1 \mathrm{wt} \%$ adsorbent.

As a result, the value per $1 \mathrm{t}$ of contaminated water was determined to be approximately $1.6 \times 10^{-4} \mathrm{~mol} / \mathrm{h}$ in mol number, and $3.6 \times 10^{-3} \mathrm{~L} / \mathrm{h}$ in volume at a normal condition.

Next, the contaminated water was treated and the hydrogen production ratio was evaluated on the assumption that $0.1 \mathrm{wt} \%$ of cesium, a fission product, was adsorbed (total $4.4 \times 10^{-2} \mathrm{wt} \%$ of radioactive ${ }^{134} \mathrm{Cs}$ and ${ }^{137} \mathrm{Cs}$ ) on the adsorbent. Assuming that all of the $\beta$-ray and $\gamma$-ray from radioactive cesium are absorbed in the contaminated water and adsorbent mixture, the radiation energy was determined to be approximately $1.9 \times 10^{6} \mathrm{~J} / \mathrm{h}$ per $1 \mathrm{t}$ of adsorbent ${ }^{15}$. When considering a mixture, it is important to assume a higher hydrogen production yield than that expected from the moisture content in a mixture based on the recognition that hydrogen is produced by the energy transferred to absorbent in addition to the blocking of the oxidation reaction of hydrogen. The hydrogen production yield was assumed to be $3.5 \times 10^{-8} \mathrm{~mol} / \mathrm{J}$ based on the results acquired from a specimen containing approximately $50 \mathrm{wt} \%$ of adsorbent; additionally, the hydrogen production rate during temporary storage after treatment by the column method and treatment by the batch method and column method were estimated. As a result, the values were approximately $6.6 \times 10^{-2} \mathrm{~mol} / \mathrm{h}$ per $1 \mathrm{t}$ of adsorbent by mol number and approximately $1.5 \mathrm{~L} / \mathrm{h}$ in volume at a normal condition.

The experiments using mordenite in this study were conducted under the framework of the voluntary activities of the Atomic Energy Society of Japan, which conducted the evaluation tests on the adsorption properties of cesium and other compounds in various adsorbents useful for the treatment of the contaminated water in the Fukushima Daiichi Nuclear Power Station. KURION Inc. kindly offered zeolite through the Tokyo Electric Power Co., Inc.

\section{References}

1) M. Nakashima, E. Tachikawa, "Radiolytic gas production from tritiated water adsorbed on molecular sieve 5A," J. Nucl. Sci. Technol., 24(1), 41-46 (1987).

2) M. Nakashima, Y. Aratono, "Radiolytic hydrogen gas formation from water adsorbed on type A zeolites," Ratiat. Phys. Chem., 41, 461-465 (1993).

3) M. Nakashima, N. M. Masaki, "Radiolytic hydrogen gas formation from water adsorbed on type Y zeolites," Radiat. Phys. Chem., 47, 241-245 (1996).

4) R. Yamada, R. Nagaishi, Y. Hatano et al., "Hydrogen production in the $\gamma$-radiolysis of aqueous sulfuric acid solutions containing $\mathrm{Al}_{2} \mathrm{O}_{3}, \mathrm{SiO}_{2}, \mathrm{TiO}_{2}$ or $\mathrm{ZrO}_{2}$ fine particles," Int. J. Hydrogen Energy, 33, 929-936 (2008)

5) G. J. Quinn, J. O. Henrie, J. Greenborg, Submerged Demineralizer System Vessel Shipment Report, GEND-035, EG\&G Idaho, Inc. (1984).

6) J.O.Henrie, D. J. Flesher, G. J. Quinn et al., Hydrogen Control in the Handling, Shipping and Storage of Wet Radioactive Waste, GEND-052, EG\&G Idaho, Inc. (1986).

7) H. H. Mai, H. Tachibana, T. Kojima, "Effect of temperature during irradiation and spectrophotometry analysis on the dose response of aqueous dichromate dosimeters," Radiat. Phys. Chem., 53, 85-91 (1998). 
8) P. A. Yakabuskie, J. M. Joseph, J. C. Wren, "The effect of interfacial mass transfer on steady-state water radiolysis," Radiat. Phys. Chem., 79, 777-785 (2010).

9) D. Zehavi, J. Rabani, "The oxidation of aqueous bromide ions by hydroxyl radicals. A pulse radiolytic investigation,” J. Phys. Chem., 76, 312-319 (1972).

10) J. A. LaVerne, M. R. Ryan, T. Mu, "Hydrogen production in the radiolysis of bromide solutions," Radiat. Phys. Chem., 78, 1148-1152 (2009).

11) E. Bjergbakke, Z. D. Draganić, K. Sehested et al., "Radiolytic products in waters part II: computer simulation of some radiolytic processes in nature," Radiochim. Acta, 48, 73-77 (1989).

12) J. H. Hubbell, S. M. Seltzer, Tables of X-ray Mass Attenuation Coefficients and Mass Energy-absorption Coefficients from $1 \mathrm{keV}$ to $20 \mathrm{MeV}$ for Elements $Z=1$ to 92 and 48 Additional Substances of Dosimetric Interest, NISTIR 5632, National Institute of Standards and Technology (1995).

13) A. J. Elliot, Rate Constants and g-values for the Simulation of the Radiolysis of Light Water over the Range $0-300^{\circ} \mathrm{C}$, AECL Research/AECL-11073, COG-94-167, Atomic Energy of Canada Limited (1994).

14) The 2011 off the Pacific Coast of Tohoku Pacific Earthquake and the Seismic Damage to the NPPs, Nuclear and Industrial Safety Agency, Japan Nuclear Energy Safety Organization (2011).

15) J. Katakura, H. Yanagisawa, Photon and Decay Data Libraries for ORIGEN2 Code Based on JENDL FP Decay Data File 2000, JAERI-Data/Code 2002-021, Japan Atomic Energy Research Institute (1994). 